\title{
AV Graft Thrombosis
}

National Cancer Institute

\section{Source}

National Cancer Institute. AV Graft Thrombosis. NCI Thesaurus. Code C114763.

Partial or complete occlusion of the lumen of an arteriovenous graft by a thrombus. 